\title{
Functional amnesia as induced by a psychological trauma
}

\author{
SVEN-AKKE CHRISTIANSON and LARS-GÖRAN NILSSON \\ University of Umed, Umed, Sweden
}

\begin{abstract}
The present study was designed to elucidate whether factors of encoding (attention), storage (consolidation), retrieval (reconstruction), or combinations of these are responsible for amnesia due to exposure to psychologically traumatic events. Subjects in four experiments were presented a series of slides consisting of photographs of faces, with each face accompanied by four verbal descriptors. For the control subjects, all faces were neutral. For the experimental subjects, faces in the middle of the series were horribly disfigured. Measurements of palmar and cardiac activity were made continuously during the stimulus presentation. Tests of free recall, cued recall, recognition, and cued recognition were used to measure memory performance of the verbal descriptors attached to the faces. Data from the physiological measurements and postexperimental interviews showed clearly that the emotional state wanted actually had been induced. Amnesia was founcl for items associated with the traumatic events. This finding was interpreted primarily in terms of encoding factors, but storage factors could not be excluded. Furthermore, anterograde amnesia was found in tests of recall but not of recognition, indicating that factors of encoding and retrieval but not of storage play a crucial role in this type of amnesia. Finally, no significant retrograde amnesia effects were obtained.
\end{abstract}

There are occasional reports in the clinical literature about patients showing memory impairment after having experienced strongly unpleasant or traumatic events. Not only is the traumatic event per se poorly remembered, but this is true also of the events preceding and succeeding this critical event. Such effects are commonly known as retrograde and anterograde amnesia, respectively.

For various practical and ethical reasons, systematic studies of such clinical amnesia effects are very sparse. Thus, in order to learn more about these clinical effects and about amnesia in general, a number of attempts to simulate situations in which amnesia can be induced have been made. One could argue that these attempts have been successful to the extent that many of these studies have demonstrated both retrograde and anterograde amnesia. However, in view of a couple of seemingly very basic differences between these and the clinical studies reported, any real evaluation of the attempt made in terms of success might seem somewhat premature.

First, the laboratory simulations reported usually do not demonstrate a memory impairment of the critical event per se. Actually, this event is typically very well remembered (see, e.g., Bond \& Kirkpatrick, 1982, Brenner,

This research was supported by a grant from the Swedish Council for Research in the Humanities and Social Sciences. The authors would like to thank Elizabeth Loftus, John Jonides, and one anonymous reviewer for their constructive comments on an earlier draft of this paper. Requests for reprints should be sent to Sven-Ake Christianson, Department of Psychology, University of Umeå, S-902 47 Umeå, Sweden.
1973, Detterman, 1976, Detterman \& Ellis, 1972, Ellis, Detterman, Runcie, McCarver, \& Craig, 1971, and Tulving, 1969). Second, the critical event usually employed in the laboratory to induce amnesia is not really a traumatic event. Rather, it is an event or an item that is critical in the sense that it differs from an otherwise homogeneous series of items. In view of this, it is not surprising to find that such a critical item is well remembered. It has long been known that such items are well remembered, and this effect is known as the "von Restorff effect" (see Wallace, 1965, for a review). One exception from this nontraumatic way of inducing amnesia is an elegant ex. periment recently reported by Loftus and Burns (1982). In this study, the subjects were presented with a short film showing an armed robbery in which a child was seriously wounded by the bullets from the robbers guns. In test of detail information associated with the critical event, Loftus and Burns were able to demon strate at least some of the amnesia effects typically found in clinical cases.

Along much the same line of thinking, one of the present authors (Christianson, in press) demonstrated amnesia effects in a laboratory setting without any von Restorff side effects. This was accomplished by presenting a picture story mimicking a traumatic event More specifically, it was a story containing three parts The beginning and the end of the story contained emo tionally neutral information, whereas the middle por tion of the story was of a traumatic nature. As a control a neutral version of the same story was presented. The beginning and end were identical to the beginning anc end parts of the traumatic version. The middle portion: 
of the two versions differed-in the neutral version, the middle portion was also neutral.

In Christianson's (in press) study, both retrograde and anterograde amnesia effects were demonstrated. Moreover, it was found that retrograde, but not anterograde, amnesia recovered over time, which is an effect found in clinical cases as well. It was also found that the traumatic event itself was remembered at just about the same level as the middle portion of the neutral version of the story. That is, there was no von Restorff effect.

Although a few important first steps have been taken in the studies by Christianson (in press) and Loftus and Burns (1982), there is more crucial knowledge to be gained about how to establish amnesia in laboratory experiments while at the same time approaching an optimal level of ecological validity. In line with this one purpose of the present study was an attempt to improve on the experimental technique employed by Christianson in order to arrive at some more firm conclusion about amnesia. An attempt was made to make the traumatic event even more traumatic or unpleasant than in Christianson's study. Moreover, an attempt was made to extend the reasoning and the analysis to another set of to-be-remembered (TBR) materials. Thus, the TBR materials were neutral associative words presented along with the traumatic event.

Three different theoretical accounts of amnesia are to be considered here. These assign the problem of amnesia to factors of encoding (attention), storage (consolidation), and retrieval (reconstruction), respectively.

Easterbrook (1959) argued that the number of cues utilized or attended to in a given situation decreases as a function of an increase in emotional arousal. States of high emotionality, arousal, and anxiety lead to an high emotionality, arousal, and anxiety lead to an intense concentration on a few main items and to poor processing of peripheral information. This process of focusing of attention would be beneficial to memory performance if peripheral cues were excluded and if no recall of such information were required. This view was extended by Mandler (1975), who proposed a mechanism ("attention-demanding characteristics of autonomic nervous system arousal") that relates emotional arousal to restricted cue utilization. "Given the limited capacity of attention-consciousness and the presence of additional events that make demands on that limited capacity, it is not surprising that with increasing arousal the number of other events (cues) that can share conscious attention will be decreased" (Mandler, 1975, p. 124). When emotional arousal becomes very intense, "it floods attentional mechanisms and decreases the amount of information that the organism can recruit effectively either from the environment or from its own memory store" (Mandler, 1975, p. 123). Thus, high levels of arousal seem to decrease memory performance because "a smaller proportion of attentional capacity is available for task processing" (Eysenck, 1982 , p. 176). Functional amnesia may then occur because high emotional arousal makes it increasingly difficult to engage in parallel or shared processing.

The consolidation process is usually viewed as time dependent (e.g., Hebb, 1949; Müller \& Pilzecker, 1900), and both retrograde and anterograde amnesia have been assumed to represent a disruption in the consolidation processes (see Glickman, 1961, for a review). Several clinical studies supporting this view have been presented (see, e.g., Jus \& Jus, 1972, Milner, 1965, 1966, Russel \& Nathan, 1946, and Scoville \& Milner, 1957). It is generally assumed that amnesics suffer from an impaired ability to consolidate information in long-term memory. Thus, short-term learning is intact, but new long-term learning cannot occur. In the case of retrograde amnesia, the critical event (the physical or psychological trauma) interrupts the perseverating neural activity responsible for forming a long-term trace. Milner, Corkin, and Teuber (1968) reported retrograde amnesia effects for recent rather than for older memories because older memories have experienced more neural activity and are therefore less susceptible to disruption. Deutsch and Deutsch (1966) suggested two different consolidation processes, one for short-term memories and one for long-term memories.

A slightly different interpretation of the locus of a similar type of memory impairment was offered in studies on the effect of arousal in learning and memory (see reviews by Berlyne, 1967, Eysenck, 1982, and Levonian, 1972). One theory relating consolidation of memory to arousal was proposed by Walker (1958). Walker's "action decrement theory" hypothesized that, in a state of high arousal, compared with low arousal, an increased nonspecific neural activity is assumed (more intense consolidation). This results in an improved longterm memory but in a lower accessibility to short-term. memory information. The deterioration of short-termmemory performance is explained in terms of a temporary inhibition of access to the memory trace during the consolidation process that serves to protect the memory trace against disruption.

One of the theories arguing for a retrieval explanation of human amnesia has been offered by Warrington and Weiskrantz. Studies in which amnesics are presented with different types of cues such as word fragments, initial letters of a word, and category information (e.g., Warrington \& Weiskrantz, 1968, 1970; Weiskrantz \& Warrington, 1970a, 1970b) have demonstrated that amnesics improve their performance to a great extent and the difference between these amnesic patients and normals is reduced considerably. The explanation proposed by Warrington and Weiskrantz (1970) is that an impaired control over stored information causes the amnesics to retrieve too much information, which makes them more vulnerable to interference than normals. Retrieval cues that narrow the range of response altematives should therefore aid amnesic performance.

Retrieval processes are generally assumed to play a 
more predominant role in recall than in recognition, in that recall involves a search or a retrieval process followed by a decision process. This search is furthermore assumed to be bypassed in recognition (see, e.g., Bahrick, 1970, and Kintsch, 1970). If high emotional arousal reduces available processing capacity, encoding opera. tions might be restricted to fewer attributes of the TBR items. This limited and shallower encoding would then be more critical for recall than for recognition operations. Furthermore, traumatic material reactivates a state of unpleasantness during the act of retrieval. A line of reasoning similar to that applied to encoding can be applied to retrieval as well. That is, given a limited capacity of conscious attention and given that retrieval processes occupy a certain amount of this limited capacity, it can be assumed that, during states of high emotional arousal, the act of recall would be more impaired than would the act of recognition.

Four experiments were designed to determine whether encoding factors, storage factors, retrieval factors, or combinations of these are responsible for the generation of amnesia effects. The presentation of a series of slides (pictures of faces and associative TBR items) involving a traumatic sequence in the middle was one basic property of the general design. Retrograde effects could then be evaluated for items preceding this traumatic event, and anterograde effects could be evaluated for items succeeding this high-arousal event. Another aim of the experiments was to compare the patterns of memory performance using different types of memory tests, that is, free recall, cued recall, recognition, and cued recognition. Cued recall was the testing procedure employed in Experiment 1. In order to avoid residual effects of arousal and recency effects, the tests were given 12 min after study.

The prerequisites were different with respect to the items preceding and succeeding the traumatic events, and with respect to the traumatic critical items themselves. In the preceding phase, there were no upsetting pictures presented and therefore no impairment in memory performance was expected. However, given a strong emotional effect due to the traumatic events presented in the middle phase, the conscious attention of the subjects was expected to be divided among the traumatic pictures, the high emotional-arousal state, and the TBR material. This division of attention was expected to result in a decrease of available resources aiding memory processing of the TBR items. Thus, a lower recall performance for the traumatic group than for the neutral group was expected. These effects of emotionality and high arousal were expected to last also to the succeeding neutral phase, and, because of this high arousal state, a limited capacity of conscious attention and, hence, a decrease in effective encoding of the TBR material, as compared with those in the neutral group, was still expected.

\section{EXPERIMENT 1}

\section{Method}

Subjects. The subjects in this experiment were 20 paid college and university students (18-30 years of age) from Umeå. To ascertain that all subjects were naive with respect to studies of this sort, no psychology students participated in the experiment. The students who knew about this experiment beforehand also were expelled from the pool of potential subjects. The subjects, who were tested individually, took part in this experiment on a voluntary basis and were given the equivalent of USD 8 each for their participation. Prior to the experiment, the subjects were interviewed about their physical and psychological status. They were also asked about their sensitivity to different kinds of emotional content in magazines and movies. The subjects were led to believe that these questions were important to exact calibration of the physiological measurements. They were also told that they could interrupt the experiment whenever they liked and still get paid for their services.

Apparatus. In order to establish physiological correlates to the psychological experiences of the stimulus material, measurements of skin conductance (SC) and heart rate (HR) were made continuously during stimulus presentation. SC was measured by means of a bioelectric amplifier and Beckman $\mathrm{Ag} / \mathrm{AgCl}$ electrodes attached to the second phalanx of the index and middle fingers of the nondominant hand. HR was measured via a bipolar diversion from thorax by Beckman $\mathrm{Ag} / \mathrm{AgCl}$ electrodes and by an integrated Mednic Biotelemetry $1 \mathrm{C}-45$ system (moving averages of $3-4$ beats). Signals for SC and HR were recorded by a Sanborn dual-channel amplifier-recorder, operating at a paper speed of $1 \mathrm{~mm} / \mathrm{sec}$. SC and HR were read as pen displacement in millimeters $(1 \mathrm{~mm}$ corresponded to approximately $0.2 \mathrm{micro}-$ mhos = 1 unit for SC, and $1 \mathrm{~mm}$ corresponded to 1 beat $/ \mathrm{min}$ for HR). The presentation of stimulus slides were automatically event marked on the paper to determine the specific arousal level in response to each slide. The slides were presented by means of two synchronized Prodovit color slide projectors attached to Munter electronic shutters. A Teleproducts timer was used to control exposure times.

Materials. Two series of 18 pairs of slides, each divided into three phases, with 6 pairs of slides in each phase, were used as stimulus material. Each pair of slides was composed of one color slide showing a human face and one showing four words describing four different characteristics to this face: a name, an occupation, a hobby, and a personality trait. The characteristics chosen were matched for word frequency both within and between phases. One of the series of slides was of neutral character and showed faces of ordinary people. This neutral version was presented to half of the subjects, and the other series of slides, supposedly being of a traumatic nature, was presented to the other half. This traumatic version was, however, identical to the neutral one with respect to the faces presented in Phase 1 and Phase 3. Phase 2 was different in that it showed a series of grotesque forensic pathology photographs of facial injuries (Gresham, 1975). The verbal descriptions presented along with the faces in the traumatic version were identical to those presented in the neutral version in all three phases. There were three random orders of the verbal descriptions presented.

Procedure. After the electrodes for the SC and HR measurements had been fastened, the subjects were assigned a seat in a dimly lit cubicle and were asked to rest for $5 \mathrm{~min}$, to allow for a baseline reading of the palmar and cardiac activity. Ear protectors of headphone type were allotted the subjects to exclude irrelevant outside noise.

Prior to the presentation of the slides, the light was turned off and one pair of slides was shown as an illustration of the materials and the procedure. The face slide of this pair was a picture of the experimenter, and the words were the category 
names to which the characteristics belonged: name, occupation, hobby, and personality trait. The particular composition of this slide was made for the sake of avoiding interference with the tobe-presented slides in the experiment proper. Each subject was instructed to read the four aspects aloud, to concentrate carefully on the face, and then to choose and report one of these aspects. The subject was to choose the aspect that he or she felt to be the most suitable for the face presented. The slides were projected through two holes in the wall behind the subject onto a screen $3 \mathrm{~m}$ in front of the subject. The aspects were presented in the upper part of the screen and the faces in the lower part of the screen, resulting in a size of $60 \times 70 \mathrm{~cm}$ for each of the two pictures. The exposure time was $17 \mathrm{sec} / \mathrm{slide}$ pair and $4 \mathrm{sec}$ between the slides. The subjects were led to believe that they were to participate in an investigation of social psychology. No mention was made about the presentation of unpleasant pictures or the forthcoming retention test.

Immediately after the subjects had viewed the whole series of 18 pairs of slides, the light was turned on again, the electrodes were detached, and the subjects were told that the experiment was almost completed. However, before being dismissed, the subjects were told that they would have to carry out a supplementary task not related to the "face-and-verbal-descriptor" task. Twelve minutes after the presentation of faces and aspects had been completed, the subjects were given an unexpected cued-recall test. To prevent rehearsal, the 12 -min interval was filled with informal discussions about various topics not related to the experiment proper.

In this cued-recall test, the subjects were presented with each face again, in the same order as in the study phase. The instructions given to the subjects were to recall as many as possible of those four aspects previously presented along with each face. The subjects made their responses aloud. There was no time limit for these recall responses. After having completed the retention test, the subjects were asked to rate to what extent they had been affected emotionally by the content of the slides. In one question, the subjects were asked to give a global rating of the slides along a dimension of pleasantness-unpleastantness ( $1=$ very pleasant; $7=$ very unpleasant $)$. The subjects were also asked to judge on a 10-point scale how distressed they had felt during the presentation of the most, if any, unpleasant picture $(1=$ not at all distressed; $10=$ very distressed). After having completed the postexperimental interview, the subjects were given an explanation of the purpose of the study.

\section{Results}

Two sets of physiological data and one set of questionnaire data were used to evaluate the level of arousal for the two groups of subjects in the present experiment. The physiological data, comprising palmar activity and cardiac activity, are presented in Figure 1. SC, presented in the left-hand panel, describes the palmar activity. The SC was read as the highest value during the presentation of each slide and then averaged across the six slides of each phase. As can be seen, there is no essential difference in baseline level between groups. However, considerable differences between groups were found for the experiment proper. These differences appear in Phases 2 and 3. SC is higher for the group presented with the traumatic materials in Phase 2 than for the group that had been presented with the neutral materials. Apparently, the difference between groups remains more or less the same even for the third phase of the experiment, although the two groups were presented with the same neutral materials in this third phase. The two groups were also presented with the same, neutral materials in Phase 1, but here there was no difference between groups in SC, since this phase occurred prior to the presentation of the traumatic materials proper.

The design used to evaluate these data statistically was a $2 \times 3$ analysis of variance and covariance (type of material $x$ phase, with the baseline measure as a covariate). There was a statistically reliable interaction between type of material and phase $[\mathrm{F}(2,36)=9.85$, $p<.01, \mathrm{MSe}=223.9]$. For the sake of tracing the source of the significant interaction, three separate oneway analyses of variance and covariance were carried out as well, one for each phase, again with the baseline level constituting the covariate. These analyses show statistically significant effects at Phase $2[F(1,53)=$

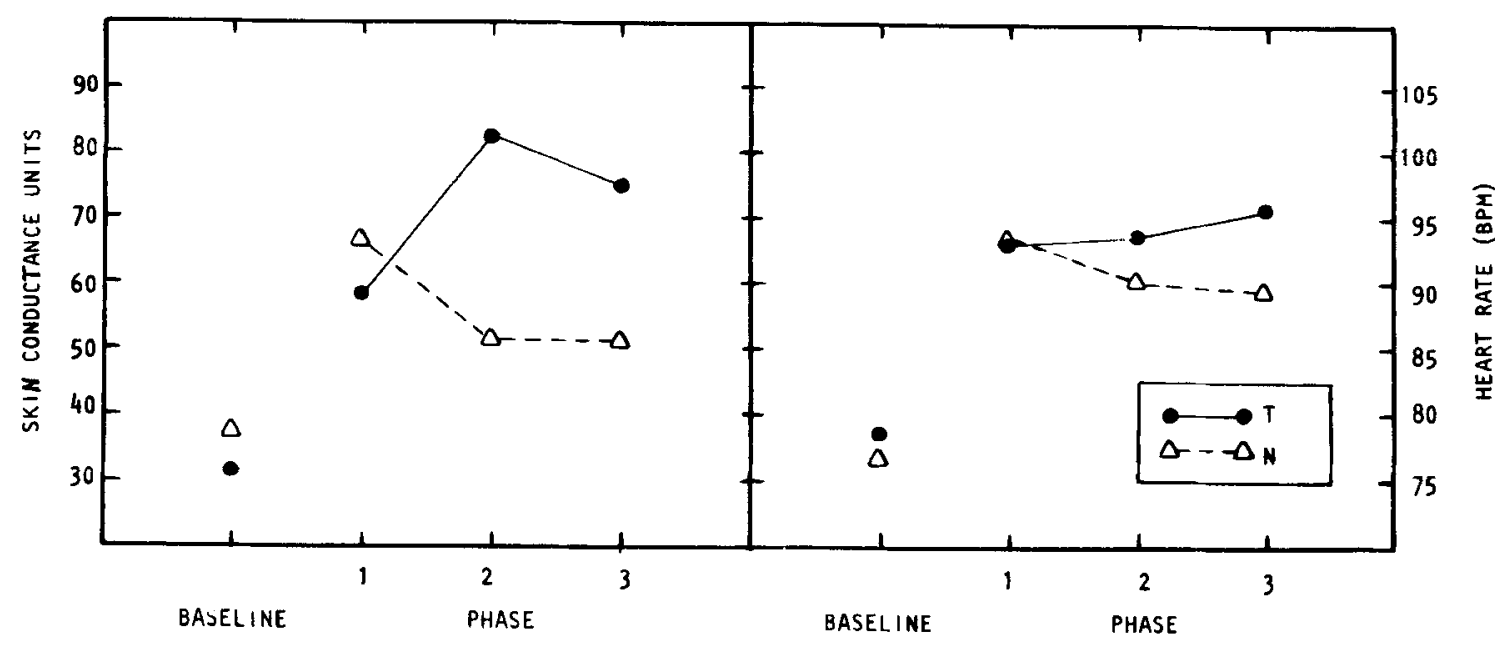

Figure 1. Baseline levels and changes in skin conductance and heart rate as a function of phase, for subjects having been presented with the neutral $(\Delta--\Delta)$ or the traumatic $(\bullet-\infty)$ stimulus material (Experiment 1 ). 
14.04, $\mathrm{p}<.01, \mathrm{MSe}=310.15]$ and Phase $3[\mathrm{~F}(1,53)=$ $7.38, \mathrm{p}<.01, \mathrm{MSe}=310.15]$. It should also be pointed out that the baseline difference was nonsignificant.

Cardiac activity was estimated by means of a HR measure. The highest value, in beats per minute, was first computed for each slide and each subject, and then averaged across the six slides of each phase to produce three values per subject, one value for each phase. These HR data, presented in the right-hand panel of Figure 1, show essentially the same pattern as the SC data. That is, there is no baseline difference and no difference between the groups for Phase 1. Phases 2 and 3 show a faster HR for the subjects having been presented with the traumatic materials. Again, a $2 \times 3$ analysis of variance and covariance (type of material $x$ phase with the baseline measure as a covariate) was carried out. There was a statistically significant interaction between type of material and phase $[\mathrm{F}(2,36)=5.60, \mathrm{p}<.01$, MSe $=$ 8.22] , and there was a significant main effect of type of materials $[F(1,17)=4.87, \mathrm{p}<.05, \mathrm{MSe}=24.88]$. The baseline difference between groups was nonsignificant $(F<1)$. Separate one-way analysis of variance and covariance (with the baseline level as a covariate) for each phase, revealed a tendency toward significance at Phase $2[\mathrm{~F}(1,53)=3.48, \mathrm{p}<.10, \mathrm{MSe}=13.57]$ and $\mathrm{a}$ significant effect at Phase $3[\mathrm{~F}(1,53)=11.76, \mathrm{p}<.01$, $\mathrm{MSe}=13.57]$.

Mean ratings given by the two groups with respect to the emotional dimension of the stimulus content $(1=$ very pleasant; $7=$ very unpleasant) were 5.6 and 3.3 for the traumatic and neutral group, respectively. A one-way analysis of variance revealed this difference to be statistically significant $[F(1,18)=21.45, p<.01$, MSe $=1.25]$. The item in which the subjects had to rate the degree of distress on a 10-point scale $(1=$ not at all distressed; $10=$ very distressed) show a mean value of 7.0 for the group presented traumatic pictures, which was significantly $(p<.01)$ higher than the mean value for the neutral group (1.0). These scorings indicate that the differences in SC data and HR data between the two groups in Phase 2 and 3 can be attributed to the emotional state of the subjects presented with the traumatic material.

The memory data of this experiment, shown in Figure 2, indicate that it is altogether more difficult for the subjects to remember the verbal items related to the traumatic materials than the verbal items related to the neutral materials. A $2 \times 3$ analysis of variance (type of material $x$ phase) carried out on these data revealed a significant main effect of type of material $[F(1,18)=$ $7.90, \mathrm{p}<.01, \mathrm{MSe}=8.913]$. As can be seen from Figure 2, there is also an interaction between type of material and phase, so that there is only a slight difference between the two groups for Phase 1 but a superior performance for the neutral group for Phases 2 and 3 . The analysis of variance showed this interaction to be statistically significant $[\mathrm{F}(2,36)=3.75, \mathrm{p}<.05$, MSe $=$ 3.607].

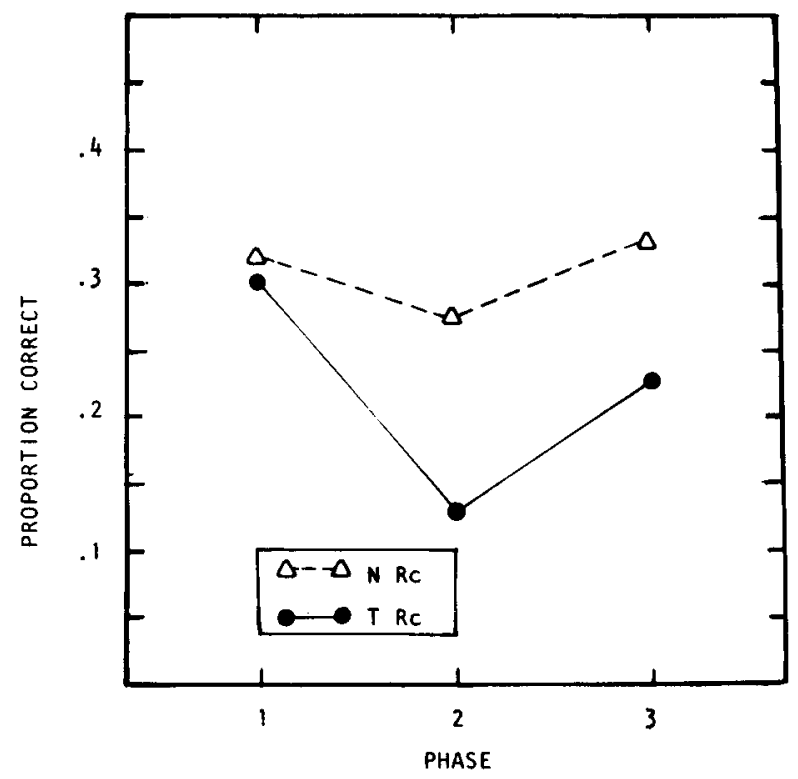

Figure 2. Cued-recall (Rc) performance as a function of phase, for subjects having been presented with the neutral $(\triangle .-\Delta)$ or the traumatic $(\bullet \rightarrow)$ stimulus material (Experiment 1).

Three separate one-way analyses of variance, one for each phase, were carried out to test simple main effects. These ANOVAs revealed significant differences between the two types of material at Phase $2[\mathrm{~F}(1,54)=10.75$, $\mathrm{p}<.01, \mathrm{MSe}=5.376]$ and Phase $3[\mathrm{~F}(1,54)=7.29$, $\mathrm{p}<.01, \mathrm{MSe}=5.376]$.

The memory data described so far have been based on recall of all four words presented with each slide at study. However, these data can be analyzed one step further. During presentation of each slide, each subject was required to select one of the four words as being the one which s(he) thought best would relate to the face presented. The mean proportions of "selected" words correctly recalled for the three phases were $.52, .33$, and .52 for the "traumatic group" and $.55, .55$, and .53 for the "neutral group." On the basis of pure inspection of these data, we can conclude that the pattern is the same as for the overall data of all four items for each slide with respect to Phases 1 and 2, but not for Phase 3 . The anterograde amnesia effect obtained for all items was not found for the items selected by the subjects.

\section{Discussion}

The SC data, the HR data, and the postexperimental interview revealed that the manipulation of stimulus material made in the experiment had had the effect intended. There was an increased palmar and cardiac activity for subjects who were presented with the traumatic materials and this is a typical pattern of physiological activity referred to in the literature as a defensive or a rejection response (e.g., Graham \& Clifton, 1966; Lacey, 1967). This holds for the traumatic phase per se 
(Phase 2), but also for the succeeding phase (Phase 3). The subjects who were presented with the traumatic version of the slides also reported in the postexperimental interview that they thought the slides presented in the middle of the series were very unpleasant. No such reports were made by the subjects in the group presented with neutral slides.

This difference in arousal and emotional state apparently affected the memory performances differently in the two groups. The data pattern obtained shows a lower recall performance for the traumatic than for the neutral group in the middle and the last phases. This is fully in line with the data pattern expected according to predictions made in terms of restricted elaboration of encoding, or disrupted/intensified consolidation operations, and also with the data pattern reported in the clinical literature. The data for the items selected by the subjects are instructive, primarily because they differ from the main data for recall of all items. When only the selected items are counted in Phase 3, there is no memory decrease for the traumatic group. This pattern of results is in line with an encoding hypothesis that predicts that high emotional arousal is associated with narrowed attention, which results in a decrease in memory performance on irrelevant or peripheral items. According to a consolidation explanation, this difference between selected and unselected items should not occur.

Thus, at an empirical level, the data pattern in this experiment is in agreement with the clinical literature showing amnesia for items associated with the traumatic events and an anterograde amnesia for those items succeeding the traumatic events. There is also some support for the assumption that the amnesia can be explained by restricted encoding operations due to limited processing capacity during a state of higin emotional arousal.

\section{EXPERIMENT 2}

One advantage with the laboratory situation, as compared with the clinical situation, is that factors at various stages of memory processes can be manipulated systematically. One finding reported in the clinical literature motivating such a systematic study is the act of recovery in cases of retrograde amnesia and also in some cases of anterograde amnesia (e.g., Nemiah, 1969; Pratt, 1977; Russel, 1971; Russel \& Nathan, 1946; Whitty \& Zangwill, 1977b). This phenomenon suggests that the "forgotten" events are properly encoded, but that the problem lies in accessing these events. Experiment 2 constituted a replication of Experiment 1 with respect to the study phase; in the test phase, however, memory performance was measured by means of a forced-choice recognition procedure. This arrangement was implemented to ascertain whether the memory deficiencies demonstrated in a recall test also show up in a recognition test in which the search process is assumed to be bypassed (see, e.g., Bahrick, 1970, and Kintsch, 1970). According to a consolidation hypothesis, interpreted either in terms of a disruption of the consolidation processes (Hebb, 1949; Müller \& Pilzecker, 1900) or in terms of a temporary-inhibition-of-memory performance due to an increase d arousal (Walker, 1958), a memory impairment would be expected for the traumatic group on short-interval tests regardless of the type of test (cued recall or cued recognition).

\section{Method}

Subjects. The subjects in Experiment 2 were 20 college and unjversity students from Umeå (18-32 years of age), who participated on terms equal to those on which the subjects in Experiment I participated.

Apparatus, Material, and Procedure. The apparatus and the material presented in the study phase were identical to those of Experiment 1. The test phase, however, was different. A cuedrecognition, rather than a cued-recall, test was employed. The test of the four descriptive aspects presented with each face was carried out by means of a four-alternative forced-choice recognition test. The four alternatives were presented on a single slide. One of the four alternatives in each of these slides had been presented in the study phase, and the others, serving as distractors, were either phonemically or semantically similar to the correct alternative. As in the recall test in Experiment 1, the subjects in this recognition test were presented with each face again in the same order as in the study phase. Thus, with each face, four test slides were presented (one slide for the four names, one for the four occupations, one for the four hobbies, and one slide for four personality traits). The test slides, presented one at a time, were exposed until the subject had responded aloud. After this retention test, the subjects were asked to fill out the same questionnairc as the subjects in Experiment 1 had.

\section{Results and Discussion}

The physiological data of Experiment 2 and the ratings of unpleasantness showed essentially the same pattern as in Experiment 1 and are therefore not presented separately. All in all, as in Experiment 1, the arousal data of the present experiment clearly indicate that the subjects in the control and experimental groups reacted differently to the stimulus material presented. Almost all subjects presented with the traumatic material showed discomfort and feelings of unpleasantness, whereas none of the subjects in the neutral group showed any similar effect.

The recognition data of Experiment 2 are summarized in Figure 3. In comparison with the recall data in Experiment 1, there are a few dissimilarities that should be noted. There is no significant main effect of type of materials, but there was a significant interaction between type of material and phase $[F(2,36)=3.78$, $\mathrm{p}<.05, \mathrm{MSe}=3.404]$. This interaction indicates a slightly superior memory performance for the traumatic group in Phase 1. In the middle phase, there is (as in Experiment 1) a lower performance for the traumatic group. In the third phase, the two groups perform at almost the same level. This result differs from that found in Experiment 1. In Phase 3 of Experiment 1, the memory performance of the traumatic group was 


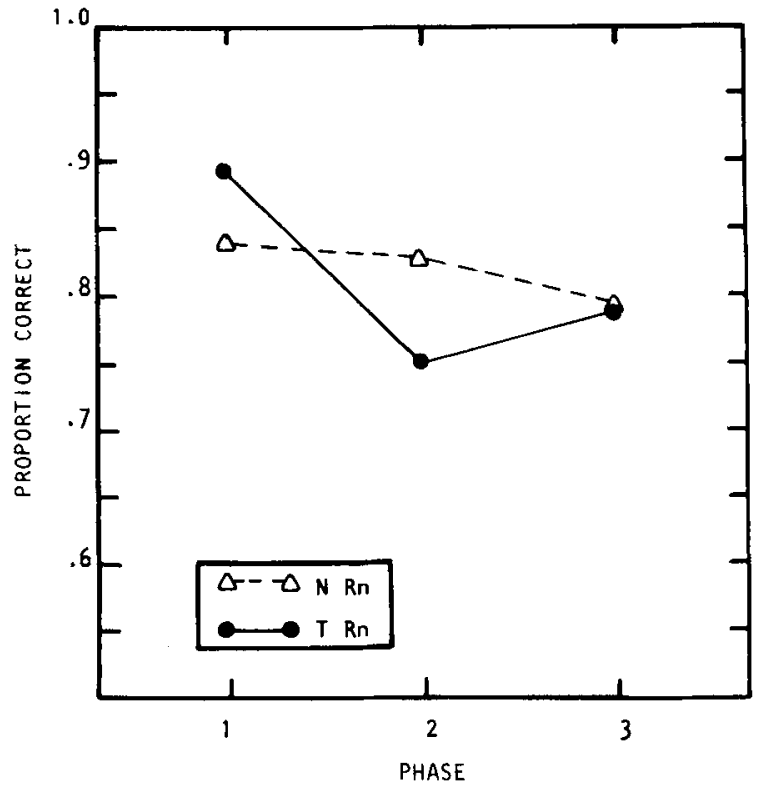

Figure 3. Cued-recognition ( $\left.R_{n}\right)$ performance as a function of phase, for subjects having been presented with the neutral $(\Delta--\Delta)$ or the traumatic $(\bullet \rightarrow)$ stimulus material (Experiment 2).

clearly below that of the control group. One-way analyses of variance for each separate phase in the present experiment revealed no significant effects.

As in Experiment 1, the mean proportions of selected words correctly recalled were computed for each of the three phases and for each group. These means were .98 , .95 , and .98 for the traumatic group and $.90, .95$, and .90 for the neutral group. As can be seen from these means, the differences between the two groups are very small. Taken together, amnesia of verbal information associated with traumatic events and events succeeding these items seems to differ depending on type of test. This finding indicates that those theoretical accounts that propose that memory deficiencies are caused by a disrupted or intensified consolidation process do not appear to provide an appropriate explanation of these effects. Encoding processes (attention) and storage processes (consolidation) should not have differed between the two experiments. Instead, it seems more reasonable to argue that amnesia, induced by traumatic and high-arousal events, is a result of restricted encoding operations and of a failure to have access to those memories properly stored.

These findings were further investigated in Experiment 3, using type of test (cued recall and cued recognition) as a within-group variable. This was done in order to determine the reliability of effects in Experiment 1 and Experiment 2. Thus, the predictions made were that, given an amnesic pattern in Phase 2 and Phase 3 in recall, this amnesia would be reduced or eliminated in a later recognition test. This pattern was also predicted to show up in tests of those specific items selected by the subjects.

\section{EXPERIMENT 3}

\section{Method}

Subjects. The subjects in Experiment 3 were 24 students from Umea (18-29 years of age). They had had no previous experience with experiments of this sort and participated on terms equal with those on which the subjects in the previous experiments participated.

Apparatus, Materials, and Procedure. The apparatus, materials, and procedure were the same as in Experiment 1, with one exception. After the subjects had finished the cued-recall test, they were also tested by the same four-alternative forcedchoiced recognition test that had been used in Experiment 2. As in the earlier studies, the interval between the last slide presented in the study phase and the initial cued-recall test was $12 \mathrm{~min}$. The time interval between study and cued-recognition test was $30 \mathrm{~min}$. The same questionnaire was administered to the subjects that had been administered in the other two experiments reported.

\section{Results and Discussion}

The physiological data and the ratings of unpleasantness show the same pattern here as in the previous two experiments and are therefore not reported in detail.

The memory data in this experiment are reported separately for cued recall and cued recognition in Figure 4. An inspection of the recall data in the left-hand panel suggests that the group exposed to the unpleasant pictures recalled fewer words in all three phases. An analysis of variance conducted on these data support this impression by showing significant main effects of type of material $[F(1,22)=16.69, p<.01, \mathrm{MSe}=4.196]$ and of phase $[F(2,44)=11.30, p<.01, \mathrm{MSe}=4.222]$. The interaction effect was nonsignificant $[F(2,44)=$ $1.99, p>.05]$. Separate one-way analyses of variance for each phase revealed significant differences in Phase 2 $[F(1,66)=15.03, p<.01, \mathrm{MSe}=1.190]$ and Phase 3 $[\mathrm{F}(1,66)=4.36, \mathrm{p}<.05, \mathrm{MSe}=1.190]$ but not in Phase 1. Inspection of the recognition data in the right hand panel of Figure 4 shows a slightly superior performance for the traumatic group in Phases 1 and 3 , whereas the control group seems to be superior in the middle phase. An ANOVA confirmed this interaction to be statistically significant $[\mathrm{F}(2,44)=12.11, \mathrm{p}<.01$, MSe $=2.870]$. Analysis of variance for the difference between the two groups in each phase revealed a significant effect in Phase 2 only $[F(1,66)=19.08, p<.01$, $\mathrm{MSe}=4.039]$.

Experiment 3 demonstrated that the effects found in recall (Experiment 1) were replicable. Thus, there was an amnesia effect for the TBR items in the traumatic phase, and there was an anterograde amnesia effect for the items succeeding this phase. No significant retrograde amnesia was found. The recognition data of Experiment 3 replicated those of Experiment 2 with regard to retrograde and anterograde amnesia; that is, no such effects were found. The amnesia found for the traumatic items (Phase 2) in recognition did not replicate the overall lack of amnesia effects for recognition in Experiment 2.

The results for those words selected by the subjects 

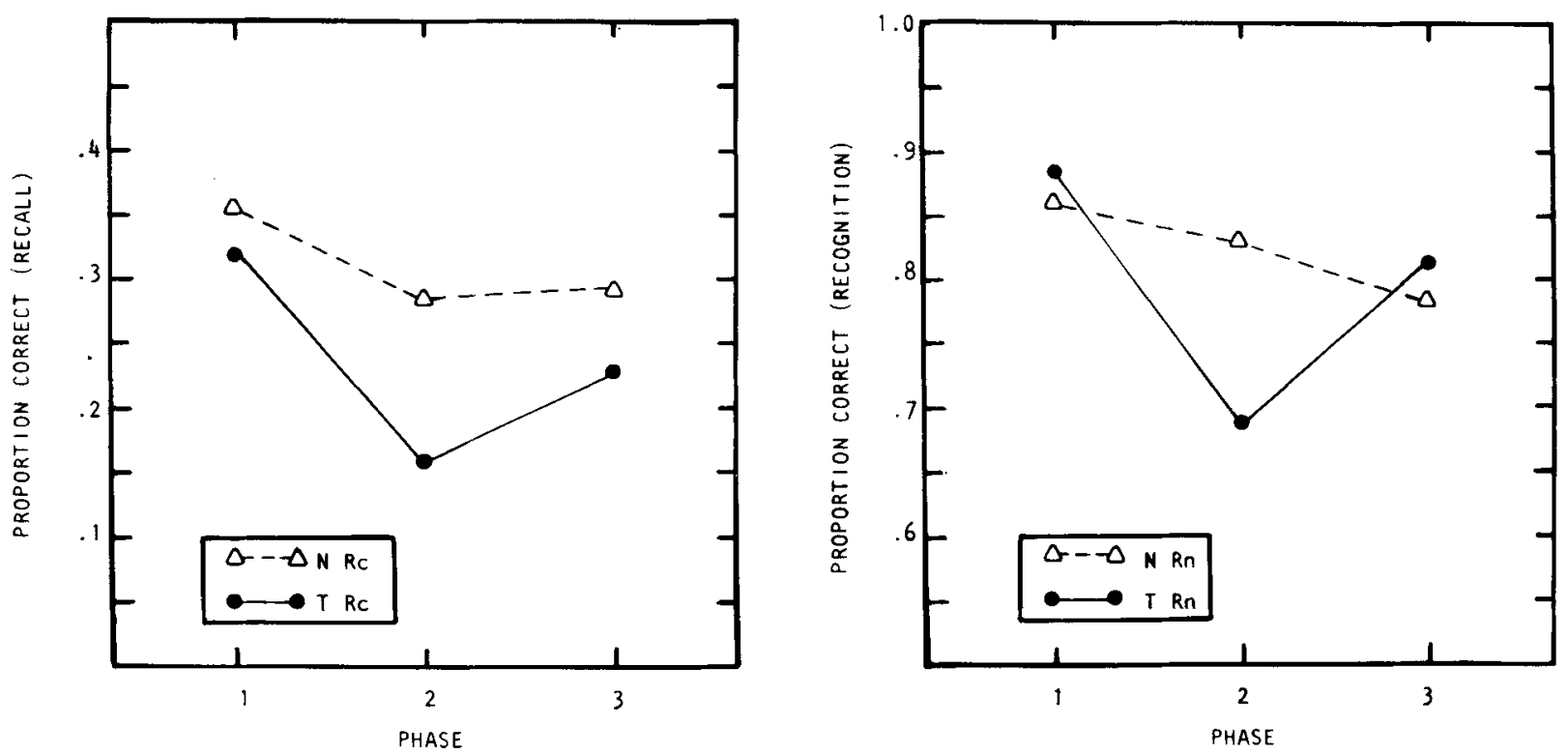

Figure 4. Cued-recall (Rc) performance (left panel) and cued-recognition (Rn) performance (right panel) as a function of phase, for subjects having been presented with the neutral $(\Delta \ldots-\Delta)$ or the traumatic $(\bullet-\rightarrow)$ stimulus material (Experiment 3).

show no significant differences between the two groups in cued recall. Means for the traumatic group are .64 , .39 , and .47 for Phases 1,2 , and 3 , respectively, and .64 , .53 , and .63 for the neutral group, respectively. The recognition data show a similar data pattern when compared with the recognition data for all items presented. Means for selected items for the traumatic group are $.96, .75$, and .93 for Phases 1,2 , and 3, respectively. For the neutral group, these means are $.92, .93$, and .92 , respectively. Thus, there was a significant interaction between type of materials and phase $[F(2,44)$ $=8.96, p<.01, \mathrm{MSe}=.354]$. In tests of simple main effects, only Phase 2 was found to be statistically significant $[F(1,66)=15.98, p<.01$, MSE $=$ $.441]$.

The data pattern obtained in these experiments does not support the consolidation theory offered by Walker (1958). One crucial test of this hypothesis was the test of recognition administered $30 \mathrm{~min}$ after the study phase. According to the literature (Eysenck, 1982), the act of consolidation should be terminated at this test interval, and one would rather expect an enhanced memory performance for the high-arousal group (cf. Kleinsmith \& Kaplan, 1963, 1964). Neither do these data fit into the disrupted-consolidation hypothesis, mainly because of the variant amnesia effects for the selected items in Phase 2.

In the three experiments reported, we have demonstrated anterograde amnesia effects in cued recall but not in cued recognition. This suggests that this type of amnesia is a result of restricted encoding operations and subsequently of a failure to have access to those items encoded only at a shallow level. The amnesia obtained in the traumatic phase (both cued recall and cued recognition) suggests that emotional arousal reduced encoding operations to too few features or attributes required for retrieval. However, failure to access might also be a part of the explanation for the amnesia of the items in the traumatic phase. As was mentioned in the introduction, the re-presentation of the traumatic faces might produce an elevated emotional arousal and thereby reduce available retrieval processing capacity (cf. Eysenck, 1982; Horowitz \& Wilner, 1976; Mandler, 1975). The re-presentation of "neutral" faces would, however, aid retrieval compared with that in cases in which no such faces are presented at test.

\section{EXPERIMENT 4}

The purpose of Experiment 4 was to investigate the effect of reduced cue information at retrieval. It is known from the literature (e.g., Tulving, 1976) that retrieval is enhanced by means of cues in recall, but not in recognition. Experiment 4 was planned in order to find out whether this general finding holds true for studies of amnesia as well. This was accomplished by using the same study procedure that had been used in Experiment 3. It might be that the face cues used in Experiments 1,2, and 3 disguised a more pure effect of arousal. If that were so, it would be expected that, when no cues were provided at test, scores would drop more dramatically in recall than in recognition, and that if any specific arousal effects were disguised by such cuing effects, the removal of cues in Experiment 4 would affect the traumatic and the neutral groups differently (see also Warrington, 1976). An alternative hypothesis would be that the horrible faces presented as cues generated a state of arousal beyond the optimal level for mental performance (Hebb, 1955). Hence, this emotional arousal would occupy a certain amount of 
processing capacity (Eysenck, 1982; Mandler, 1975), and therefore it could be expected that a withdrawal of these faces at test would be beneficial for retrieval. Thus, the amnesic effects obtained in Experiments 1 and 3 would be expected to be less pronounced in Experiment 4.

\section{Method}

Twenty-four college and university students and nonstudents from Umea (18-33 years of age) were tested similarly to the subjects in the previous experiments in this study. The experimental setup was the same as in Experiment 3, except for one change in the test procedure. In the test of recall, 12 min after the study phase, the subjects were not given any face to guide memory retrieval. Instead, the subjects were instructed to recall freely as many verbal items as possible of those presented earlier. After this recall test, 30 min after the study phase, the subjects were given a recognition test without any faces as retrieval cues; that is, the test words were not accompanied by the faces presented during the study phase.

\section{Results and Discussion}

The physiological data of Experiment 4 and the ratings of unpleasantness show essentially the same pattern as that in the previous three experiments and are therefore not reported in detail. Both SC and HR increased for the experimental group in Phase 2, in which the unpleasant pictures were presented. This effect of autonomic arousal appeared in Phase 3 as well. There were no differences between groups in SC or HR, either for baseline or for Phase 1. Taken together, these emotional/arousal data were in agreement with the expectations made.

The recall and recognition data of the present experiment are presented in Figure 5. The recall and recognition effects found in the previous experiments were found in this experiment as well. Considering the recall data in the left-hand panel of Figure 5, the experimental group appears to be inferior to the control group in all three phases. In an overall analysis of variance, this difference in type of material was found to be significant $[\mathrm{F}(1,22)=18.64, \mathrm{p}<.01, \mathrm{MSe}=5.640]$. There was also a significant interaction between type of material and phase $[F(2,44)=3.93, p<.05, \mathrm{MSe}=3.087]$. Separate one-way analyses of variance for each phase confirmed these impressions to be statistically significant in Phase 2 $[F(1,66)=24.38, \mathrm{p}<.01, \mathrm{MSe}=3.938]$ and Phase 3 $[\mathrm{F}(1,66)=6.09, \mathrm{p}<.05, \mathrm{MSe}=3.938]$ but not in Phase $1[\mathrm{~F}(1,66)=2.38, \mathrm{p}>.05, \mathrm{MSe}=3.938]$

Thus, this recall pattern shows an amnesia for the items presented in the critical phase and an anterograde amnesia for the items succeeding this critical phase. There was also a slight retrograde amnesia, which, however, did not reach a significant level.

The recognition data presented in the right-hand panel of Figure 5 show, in contrast to the recall data, a similar performance for the two groups in Phase 1 and 3 , and still an inferior performance for the traumatic group in the middle phase. The interaction between type of material and phase was significant at the .01 level $[F(2,44)=5.75, p<.01, \mathrm{MSe}=3.194]$. Separate one-way ANOVAs for each phase revealed a significant effect for Phase $2[\mathrm{~F}(1,66)=12.03, \mathrm{p}<.01$, MSe $=$ 5.540]. Thus, the anterograde amnesia obtained in the recall test and the perceptible decrement in Phase 1 were nonexistent in the recognition test. This recovery was, however, not found for the items in the traumatic phase.

In examination of the data for those words specifically selected by the subjects, a similar pattern was found for both recall and recognition performance. In recall, the means for the three phases were $.46, .26$,
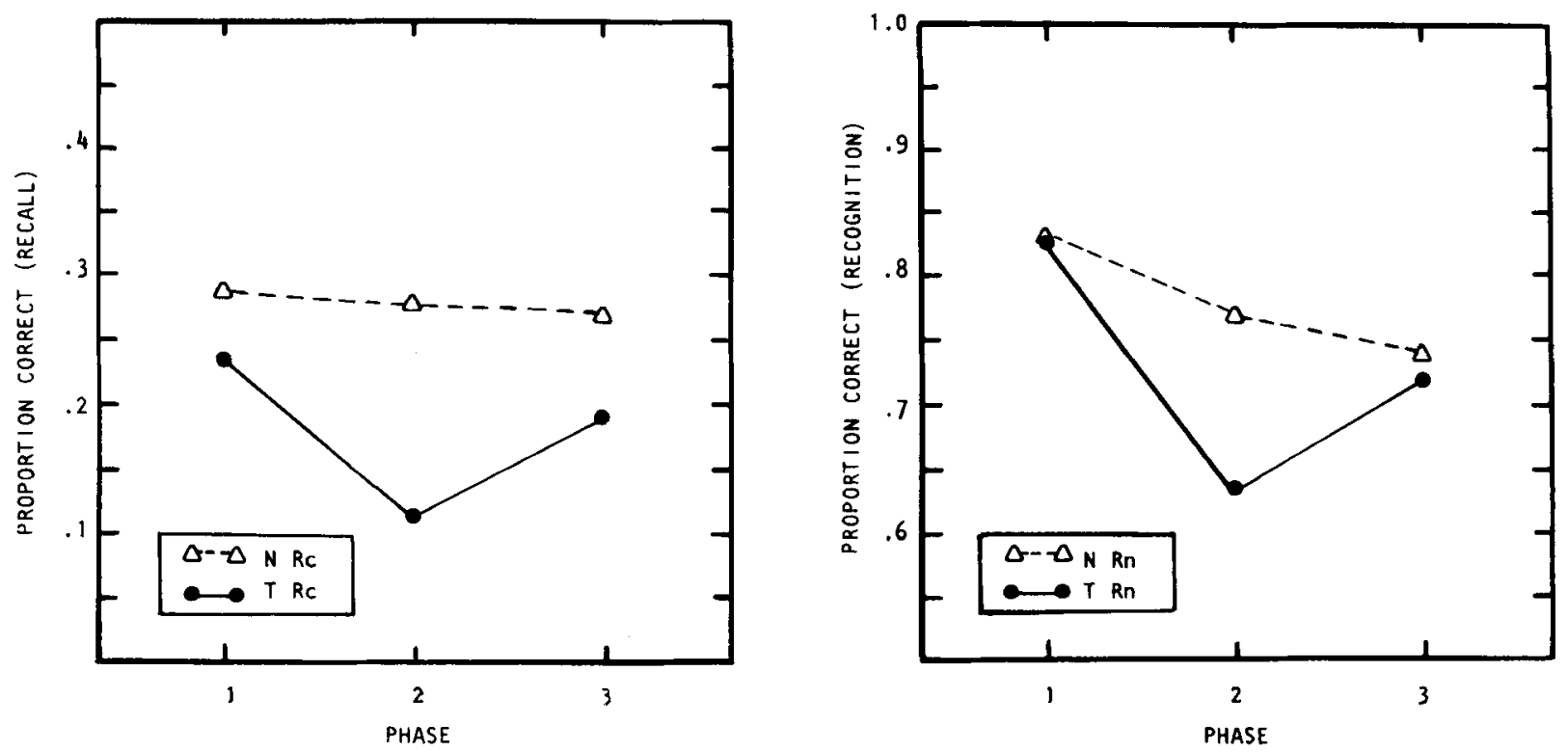

Figure 5. Recall (Rc) performance (left panel) and recognition $(\mathrm{Rn})$ performance (right panel) as a function of phase, for subjects having been presented with the neutral $(\Delta-\cdots)$ or the traumatic $(\bullet-\infty)$ stimulus material (Experiment 4$)$. 
and .36 for the traumatic group and $.54, .49$, and .54 for the neutral group. The analysis of variance revealed that only the main effect of type of material was statistically significant $[\mathrm{F}(1,22)=8.26, \mathrm{p}<.01, \mathrm{MSe}=2.059]$. For recognition, the means for selected items for the three phases were $.92, .74$, and .90 for the traumatic group and $.90, .92$, and .85 for the neutral group. In a statistical analysis of these recognition data, the same type of interaction (type of material $x$ phase) was found for selected items that was found when the calculations were made for all items presented to the subjects. This interaction was statistically significant at the .05 level $[F(2,44)=4.43, p<.05, \mathrm{MSe}=0.775]$. Separate one-way ANOVAs revealed a significant effect in Phase 2 $[\mathrm{F}(1,66)=8.66, \mathrm{p}<.01, \mathrm{MSe}=.813]$.

Considering the data in this experiment, the follow. ing conclusions can be drawn: First, as in Experiment 3 , the anterograde amnesia obtained in the recall test was not found when subjects were tested by means of a recognition test. This pattern was also obtained in Phase 1, although it was less pronounced and nonsignificant. The amnesia found in Phase 2 was not affected by type of test. Second, the difference in recall performance between the experimental group and the control group was more pronounced in this experiment than in Experiment 3. Thus, the withdrawal of cuing information seems to have affected the traumatic group more negatively than the neutral group, indicating that amnesia is due partly to retrieval difficulties. Third, the recovery effect in the recognition test does not seem to have been different in this experiment when a long retention interval was used from the effect in Experiment 2 when a short retention interval was used.

\section{ADDITIONAL ANALYSES}

To clarify a few critical aspects of the data, some additional analyses were carried out. In order to obtain maximum power in the statistics, the data in these cases were combined across experiments. Therefore, these analyses are reported separately here, rather than for each experiment.

The first aspect to be reported is the failure to establish any retrograde amnesia effects. Judging by pure inspection of the data presented, some signs of retrograde amnesia were present throughout the experiments. However, when these effects were tested in each experiment, none proved to be significant, and one might therefore argue that we have ruled out the possibility of retrograde amnesia too hastily. Moreover, the way in which we have performed the analyses so far may not have been the most appropriate one. For example, it might be that retrograde effects held true only for the last item presented in Phase 1 just before the presentation of the six traumatic slides in Phase 2. In line with this, a more adequate way to go about testing retrograde effects would be to consider only this sixth item of Phase 1 and to use the first item of that phase as a com- parison. This was done in this first additional analysis. Two separate analyses were made, one for recall and one for recognition. The ANOVA conducted used a 2 (traumatic vs. neutral materials) x 3 (Experiments 1 vs. 3 vs. 4) $\times 2$ (Phase 1 , Item 1 vs. Phase 1 , Item 6) design for recall. However, this analysis did not reveal the main effect of item that we expected in Phase 1. Actually, Item 6 was slightly better recalled than was Item 1 (means $=.27$ and .32 , respectively).

Separate analyses were also carried out for selected and nonselected items as defined previously. None of these two analyses revealed any significant effect of items in Phase 1, and it seems reasonably fair to conclude that no retrograde amnesia effects were demonstrated for recall in the present experiments.

When the same analyses were done for recognition, the design employed was 2 (traumatic vs. neutral materials) $\times 3$ (Experiments 2 vs. 3 vs. 4) $\times 2$ (Phase 1, Item 1 vs. Phase 1 , Item 6 ). There were no significant main effects of item in Phase $1(\mathrm{Fs}<1)$ for all items, selected items, or nonselected items. Thus, on the basis of these additional analyses for both recall and recognition, we conclude that no retrograde amnesia was obtained in the experiments reported.

The second additional analysis to be reported deals with selected and nonselected items. For each experiment, we have reported means for selected items in each phase and for each group. Due to low statistical power, ANOVAs have not been reported for each separate experiment. In order to obtain maximum power, we have combined the data across experiments. This has been done separately for recall and recognition. As can be seen from Figure 6, in which these data are depicted, memory performance for both selected and nonselected items is reported.

The ANOVA for recall of selected items used a 2 (traumatic vs. neutral materials) $\times 3$ (Experiments 1 vs. 3 vs. 4) $\times 3$ (Phase 1 vs. 2 vs. 3) design. This analysis revealed a main effect of type of materials $[F(1,62)=$ $13.73, \mathrm{p}<.01, \mathrm{MSe}=1.68]$ and a tendency toward an interaction between type of materials and phase $[F(2,124)=2.63, p<.10, \mathrm{MSe}=1.38]$. To trace the source of this tendency toward interaction, a separate 2 (traumatic vs, neutral materials) $\times 3$ (Experiments 1 vs. 2 vs. 3) ANOVA was carried out for each phase. Significant main effects of type of material were found for Phase $2[\mathrm{~F}(1,186)=14.50, \mathrm{p}<.01, \mathrm{MSe}=1.48]$ and Phase $3[\mathrm{~F}(1,186)=5.98, \mathrm{p}<.05, \mathrm{MSe}=1.48]$.

The same design was used for the ANOVA for nonselected items. This analysis revealed main effects of materials $[\mathrm{F}(1,62)=33.65, \mathrm{p}<.01, \mathrm{MSe}=3.48]$ and of phase $[\mathrm{F}(2,124)=18.35, \mathrm{p}<.01, \mathrm{MSe}=1.96]$, and a materials $x$ phase interaction $[\mathrm{F}(2,124)=6.99, \mathrm{p}<.01$, $\mathrm{MSe}=1.96]$. In order to trace the source of this interaction, a separate ANOVA was carried out for each phase. The design employed was 2 (traumatic vs. neutral materials) $\times 3$ (Experiments 1 vs. 2 vs. 3 ). These analyses revealed significant main effects of type of material 

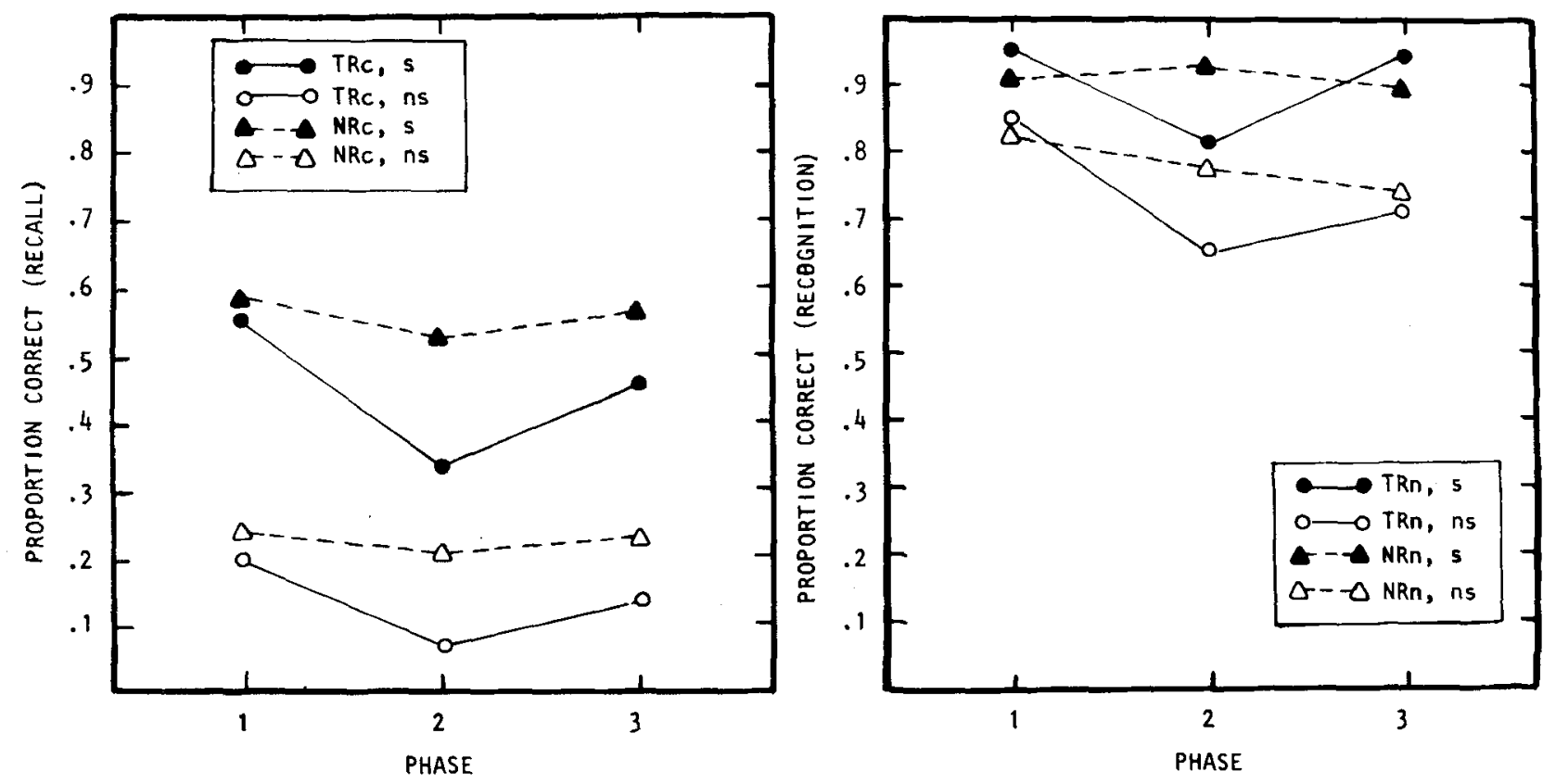

Figure 6. Recall performance (left panel) and recognition performance (right panel) for selected (s) and nonselected (ns) items as $\mathbf{a}$ function of phase, for subjects having been presented with the neutral $(4-\cdots, \Delta-. \Delta)$ or the traumatic $(\bullet-, 0-0)$ materials (Experiments 14 ).

in Phase $2[\mathrm{~F}(1,184)=39.76, \mathrm{p}<.01, \mathrm{MSe}=2.49]$ and Phase $3[\mathrm{~F}(1,184)=15.59, \mathrm{p}<.01, \mathrm{MSe}=2.49]$.

For the recognition data, the basic design was 2 (traumatic vs. neutral materials) $\times 3$ (Experiments 2 vs. 3 vs. 4) $\times 3$ (Phases 1 vs. 2 vs. 3 ). This design was em. ployed in separate ANOVAs for selected and nonselected items, respectively. The effects of interest for selected items were a main effect of phase $[F(2,124)$ $=4.20, \mathrm{p}<.05, \mathrm{MSe}=.51]$ and a materials $\mathrm{x}$ phase interaction $[\mathrm{F}(2,124)=11.42, \mathrm{p}<.01, \mathrm{MSe}=.51]$. In order to trace the source of this interaction, a separate $2 \times 3$ (type of material $\times$ experiment) ANOVA was carried out for each phase. A statistically significant main effect of type of material was found for Phase 2 $[\mathrm{F}(1,184)=15.64, \mathrm{p}<.01, \mathrm{MSe}=.56]$ but not for Phases 1 and 3.

For nonselected items, the ANOVA revealed a main effect of materials $[F(1,62)=4.13, p<.05$, MSe $=$ $6.59]$, a main effect of phase $[\mathrm{F}(2,124)=41.66, \mathrm{p}<$ $.01, \mathrm{MSe}=2.30]$, and a materials $\mathrm{x}$ phase interaction $[F(2,124)=12.72, p<.01, \mathrm{MSe}=2.30]$. In order to trace the source of this interaction, a separate $2 \times 3$ (type of material $x$ experiment) ANOVA was carried out for each phase. A statistically main effect of type of material was found for Phase $2[F(1,184)=22.00, p<$ $.01, \mathrm{MSe}=3.77$ ] but not for Phases 1 and 3 .

\section{GENERAL DISCUSSION}

A first prerequisite for studying the effects of emotions on memory is to determine whether the emotional state wanted has actually been induced. With regard to the four experiments reported in this paper, the data from measurements of palmar and cardiac activity and the postexperimental interviews provided clear evidence that the manipulation had the intended effect of inducing emotional arousal.

Given that a different state of emotional arousal has been induced in the experimental (traumatic) groups as compared with the control (neutral) groups, the next step is to determine to what extent differences in the pattern of memory data have been obtained. The experiments presented here clearly demonstrate a data pattern for the experimental groups that was different from that for the neutral groups. In general, there is a lower recall and recognition performance for the experimental than for the control groups in Phase 2. This is an important finding, since it mirrors the data typically obtained in clinical settings. As mentioned in the introductory section, the absolute majority of studies inducing amnesia in the laboratory have demonstrated a high memory performance for critical items or items associated with the critical event. The lack of such a von Restorff effect in the present study provides an important prerequisite for proper comparisons to clinical cases.

With respect to Phase 1 items, both storage and retrieval factors could be involved for explaining any possible retrograde amnesia. Encoding factors should not be involved for such a form of amnesia, since these Phase 1 items have already been registered and encoded when the traumatic events are presented for the experimental groups in Phase 2. The two groups should not differ with respect to recall or recognition of Phase 1 
items, since the manipulations made do not differ between groups. And indeed, no difference between groups for these items were found in any of the four experiments; that is, there is no retrograde amnesia. If storage or retrieval factors had played a crucial role for memory of Phase 1 items, one would have expected a difference in the data pattern between groups.

One reliable finding in this study was the amnesia obtained for the items attached to the traumatic pictures. For these Phase 2 items, encoding, storage, and retrieval processes could have been involved. With respect to encoding, the assumptions made were that the traumatic pictures cause a reallocation of processing resources to the horrible faces, the verbal descriptions attached to the faces, and the increased autonomic arousal (emotionality effect). It was further suggested that this division of attentional resources would restrict encoding operations to fewer features or attributes of the TBR material or, altematively, to an increased atten. tional selectivity.

Thus, on the basis of the assumption that high emotional arousal results in a reduction of attentional resources available for processing of the TBR items, one would expect that subjects remember less well if there is a compound of items to remember. This is the case when all the TBR items are considered. However, if restriction of encoding is associated with attentional selectivity, one would expect subjects in the traumatic group to focus their attention and thus to perform as well as subjects in the neutral group for selected items. This was also the result obtained for cued recognition in Experiment 2 and for cued recall in Experiment 3. In Experiment 1 (cued recall), Experiment 3 (cued recognition), and Experiment 4 (both recall and recognition), however, performance for the traumatic group was lower than that for the neutral group, even for selected items. When these data were combined across experiments, a significant decrease in performance was found for these items. This decrease in performance for selected items can be interpreted in different ways. Provided that encoding constitutes the locus of this amnesia for critical items, the decrease in memory performance is due most likely to the subjects' attempts to cope with the horrible pictures, thereby diminishing their efficiency in processing of the verbal items related to these pictures. What about storage factors? According to the consolidation hypothesis proposed by Walker (1958), discussed in the introduction, one crucial prediction was that memory performance should improve as a function of time between study and test. This prediction can be evaluated by comparing the data for Experiment 2, on the one hand, and for Experiments 3 and 4, on the other. In Experiment 2, the recognition test was given soon after study, whereas, in Experiments 3 and 4, this test was given some $30 \mathrm{~min}$ later. A comparison of the data in Figures 3, 4, and 5 indicates no improvement in the data in Figures 4 and 5, and it is therefore concluded that an interpretation in terms of an augmented consolidation process seems less likely. An alternative interpretation on the basis of storage factors is that of a disrupted consolidation. In spite of the fact that the recognition data of all items and selected items in Phase 2 of Experiment 2 is at variance with such a hypothesis, the combined recognition data in Experiments 2, 3, and 4 demonstrate that this hypothesis cannot be rejected. Since amnesia was obtained in cued recall (Experiment 1) but not in cued recognition (Experiment 2), we maintain that a retrieval explanation is applicable for these data. Although encoding factors may play a dominating role for the data obtained in Phase 2 , the possibility of disrupted consolidation cannot be ruled out entirely.

Whereas differences were found between experimental and control groups for Phase 2 items, irrespective of retention test (see Additional Analyses), the results for Phase 3 items differed between recall and recognition. Anterograde amnesia was found in recall but not in recognition. The lack of anterograde amnesia in recognition was demonstrated both when the test was given soon after study (Experiment 2) and when it was given after a more extended period of time (Experiments 3 and 4). In line with most current thinking found in memory literature, we assume somewhat different types of retrieval operations in recall and recognition. For example, according to Baddeley (1976), Bahrick (1970), and Kintsch (1970), a more extended memory search is required in recall than in recognition. Thus, it seems reasonable to conclude that the anterograde amnesia obtained here is most likely due to disturbances at retrieval, and that various hypotheses about failure of consolidation (see Whitty \& Zangwill, 1977a) are less adequate for explaining these data.

By comparing the results from Experiments 3 and 4, conclusions can be drawn about the effect of retrieval cues in both recall and recognition. Without faces as cues, there is an overall lower level of performance. However, the pattern of data does not seem to be affected by cues. This is especially true for recognition; the pattern of data is exactly the same in Experiments 3 and 4 , both with respect to all items and with respect to selected items only. For recall there is a slight difference between the two experiments. In Experiment 4, in which no cues were given, there was a significant difference between groups, both for all items and for selected items only. When cues were given (Experiment 3), the difference between groups reached significance only for all items. Thus, there is a slight positive effect of retrieval cues in recall but not in recognition, and this effect is more pronounced for selected items.

An additional interpretation of the Phase 3 data (anterograde amnesia) is possible. Due to a lasting higharousal state from Phase 2 and to a possible perseveration in thinking about the horrible pictures (see Horowitz \& Wilner, 1976, and Zachary, 1982), the subjects may fail to encode the Phase 3 items in an elaborative and efficient way. However, a more shallow encoding may suffice in recognition but not in recall (cf. Lockhart, Craik, \& Jacoby, 1976). That is, encoding by the subjects in the traumatic groups is deep enough to manage the less 
demanding recognition procedure. In order to manage the search or reconstructive processes involved in recall, a deeper or more elaborate encoding is needed. This type of relationship between encoding and retrieval has also been proposed as an explanation for the amnesia demonstrated in Korsakoff patients (Talland, 1965) and in posthypnotic amnesia (Kihlstrom \& Evans, 1979). However, as will be discussed next, we do believe that great caution should be taken in attempting to incorporate the amnesia demonstrated in different groups of patients and subjects in one single heading.

Ellis et al. (1971) arrived at the same conclusion that storage factors could possibly not be involved since the anterograde effect was larger than the retrograde effect. As noted, such a difference between the size of anterograde and retrograde effects was also obtained here, and, in this respect, the conclusions made are in line with those of Ellis et al. However, the interpretations of the anterograde effects obtained here and in Ellis et al. differ. Whereas a joint encoding and retrieval explanation was offered here, Ellis et al. argued for a singlefactor explanation, for which only encoding difficulties were said to be repsonsible for the anterograde effects. Since we obtained anterograde effects in recall but not in recognition, our interpretation seems at least as likely and as reasonable as the Ellis et al. interpretation. The question of primary concern is, therefore, why the data obtained here and in the Ellis et al. study differ.

Whereas we employed a "traumatic" emotional load on the TBR materials, Ellis et al. (1971) did not. This difference in materials might be crucial for the differences in the data obtained. It seems reasonable to assume that different cognitive capabilities could be involved when different demands are present in each experimental situation. At any rate, the differences in data obtained here and in the Ellis et al. study should be taken to indicate that different underlying factors might be involved in amnesia, depending on the type of materials and the situation used to induce the amnesia. Although it is appealing to search for common underlying mechanisms in amnesia, it may yet be too premature an enterprise. The present data suggest that greater consideration should be given to differences in situational demands, even though we happen to use the same label (e.g., anterograde amnesia) for seemingly similar effects obtained in different situations.

Assuming such a functionalistic approach (e.g., Nilsson, 1980, 1984), in which the interaction between cognitive capabilities and task demands, rather than the cognitive capabilities in isolation, is considered, caution should also be employed when attempts are made to incorporate data from different subject pools in single interpretations of amnesia. For example, it has been claimed that the anterograde amnesia in Korsakoff's disease should be understood as a defect of encoding or initial learning rather than as a defect of retrieval (see Huppert \& Piercy, 1982). Although it may seem reasonable to interpret such data in terms of encoding, it may be wise to realize that these encoding factors could be radically different from the encoding factors Ellis et al. (1971) referred to as responsible for the anterograde effects they obtained. From a functionalistic point of view, it is reasonable to recognize such a possibility, although the empirical effects look the same and the concepts used to interpret the data are the same.

\section{REFERENCES}

BAdDELEY, A. D. (1976). The psychology of memory. New York: Basic Books.

BAнRick, H. P. (1970). Two-phase model for prompted recall. Psychological Review, 77, 215-222.

BerLyNe, D. E. (1967). Arousal and reinforcement. In D. Levine (Ed.), Nebraska Symposium on Motivation. Lincoln: University of Nebraska Press.

Bond, C. F., JR., \& KirkPatrick, K. C. (1982). Distraction, amnesia, and the next-in-line effect. Journal of Experimental Social Psychology, 18, 307-323.

Brenner, M. (1973). The next-in-line effect. Journal of Verbal Learning and Verbal Behavior, 12, 320-323.

Christianson, S.- $\AA$. (in press). The relationship between induced emotional arousal and amnesia. Scandinavian Journal of Psychology.

Dette rman, D. K. (1976). The retrieval hypothesis as an explanation of induced retrograde amnesia. Quarterly Journal of Experimental Psychology, 28, 623-632.

Detterman, D. K., \& Ellis, N. R. (1972). Determinants of induced amnesia in short-term memory. Journal of Experimental Psychology, 95, 308-316.

Deutsch, J. A., \& Deutsch, D. (1966). Physiological Psychology. Homewood, IL: Dorsey.

Easters rook, J. A. (1959). The effect of emotion on cue utilization and the organization of behavior. Psychological Review, 66, 183-201.

Ellis, N. R., Detterman, D. K., Runcie, D., McCarver, R. B., \& Craig, E. M. (1971). Amnesic effects in short-term memory. Journal of Experimental Psychology, 89, 357-361.

EYSENCK, M. W. (1982). Attention and arousal: Cognition and performance. Berlin: Springer-Verlag.

Glickman, S. E. (1961). Perseverative neural processes and consolidation of the memory trace. Psychological Bulletin, 58, 218-233.

Graham, F., \& Clitron, R. (1966). Heart rate change as a component of the orienting response. Psychological Bulletin, 65, 305-320.

Gresham, A. G. (1975). A colour atlas of forensic pathology. London: Wolfe Medical Books.

HEBB, D. O. (1949). The organization of behavior. New York: Wiley.

HEBB, D. O. (1955). Drives and the C. N. S. (conceptual nervous system). Psychological Review, 62, 243-254.

Horowitr, M., \& Wilner, N. (1976). Stress films, emotion, and cognitive response. Archives of General Psychiatry, 33, 1339-1344.

Huppert, F. A., \& Piercy, M. (1982). In search of the functional locus of amensic syndromes. In L. S. Cermak (Ed.), Human memory and amnesia. Hillsdale, NJ: Erlbaum.

Jus, K., \& Jus, A. (1972). Experimental studies on memory disturbances in humans in pathological and physiological conditions. International Journal of Psychobiology, 2, 205-218.

Kinlstrom, J. F., \& Evans, F. J. (1979). Memory retrieval processes during posthypnotic amnesia. In J. F. Kihlstrom \& F. J. Evans (Eds.), Functional disorders of memory. Hillsdale, NJ: Erlbaum.

Kıntsch, W. (1970). Models for free recall and recognition. In 
D. A. Norman (Ed.), Models of human memory. New York: Academic Press.

Kleinsmith, L. J., \& Kaplan, S. (1963). Paired-associate learning as a function of arousal and interpolated interval. Journal of Experimental Psychology, 65, 190-193.

KLEINSMith, L. J., \& KAPLAN, S. (1964). Interaction of arousal and recall interval in nonsense syllable paired-associate learning. Journal of Experimental Psychology, 67, 124-126.

LACEY, J. (1967). Somatic response patterning and stress: Some revisions of activation theory. In $\mathbf{M}$. Appley \& $\mathbf{R}$. Trumbull (Eds.), Psychological stress: Issues in research. New York: Appleton-Century-Crofts.

Levonian, E. (1972). Retention over time in relation to arousal during learning: An explanation of discrepant results. Acta Psychologica, 36, 290-321.

Lockhart, R. S., Craik, F. I. M.. \& Jacoby, L. (1976). Depth of processing, recognition and recall. In J. Brown (Ed.), Recall and recognition. London: Wiley.

LofTus, E. F., \& Burns, T. (1982). Mental shock can produce retrograde amnesia. Memory \& Cognition, 10, 318-323.

Mandler, G. (1975). Mind and emotion. New York: Wiley.

Milner, B. (1965). Memory disturbances after bilateral hippocampal lesions. In P. Milner \& S. Glickman (Eds.), Cognitive processes and the brain. New York: Von Nostrand.

Milner, B. (1966). Amnesia following operation on the temporal lobes. In C. W. Whitty \& O. L. Zangwill (Eds.), Amnesia. London: Butterworth.

Milner, B., Corkin, S., \& Teuber, H. L. (1968). Further analysis of the hippocampal amnesic syndrome: 14-year followup study of H. M. Neuropsychologia, 6, 215-234.

Müllek, G. E., \& Pilzecker, A. (1900). Experimentelle Beitrage zur Lehre vom Gedächtnis. Zeitschrift für Psychologie, 1, 1-300.

Nemiah, J. C. (1969). Hysterical amnesia. In G. A. Talland \& N. C. Waugh (Eds.), The pathology of memory. New York: Academic Press.

NiLsson, L.-G. (1980). Methodological and theoretical considerations as a basis for an integration of research on memory functions in epileptic patients. Acta Neurologica Scandinavica, 62 (Suppl. 80), 62-74.

NiLsson, L.-G. (1984). New functionalism in memory research. In K. Lagerspetz \& P. Niemi (Eds.), Psychology in the 1990's. Amsterdam: North-Holland.

Pratt, R. T. C. (1977). Psychogenic loss of memory. In C. W. M.
Whitty \& O. L. Zangwill (Eds.), Amnesia (2nd ed.). London: Butterworth.

Russel, W. R. (1971). The traumatic amnesias. London: Oxford University Press.

Russel, W.R., \& Nathan, P. W. (1946). Traumatic amnesia. Brain, 69, 280-300.

Scoville, W. B., \& Milner, B. (1957). Loss of recent memory after bilateral hippocampal lesions. Journal of Neurology, Neurosurgery, and Psychiatry, 20, 11-21.

Talland, G. A. (1965). Deranged memory. New York: Academic Press.

Tulving, E. (1969). Retrograde amnesia in free recall. Science, 164, 88-90.

Tulving, E. (1976). Ecphoric processes in recall and recognition. In J. Brown (Ed.), Recall and recognition. London: Wiley.

WALKER, E. L. (1958). Action decrement and its relation to learning. Psychological Review, 65, 129-142.

Wallace, W. P. (1965). Review of the historical, empirical, and theoretical status of the von Restorff phenomenon. Psychological Bulletin, 63, 410-424.

Warkington, E. (1976). Recognition and recall in amnesia. In J. Brown (Ed.), Recall and recognition. London: Wiley.

Warkinaton, E. K., \& Weiskrantz, L. (1968). A new method of testing long-term retention with special reference to amnesic patients. Nature, 217, 972-974.

Warrington, E. K., \& Weigkrantz, L. (1970). Amnesic syndrome: Consolidation or retrieval? Nature, 228, 628-630.

Weiskrantz, L., \& Warkinaton, E. K. (1970a). A study of forgetting in amnesic patients. Neuropsychologia, 8, 281-288.

Weiskrantz, L., \& Warrington, E. K. (1970b). Verbal learning and retention by amnesic patients using partial information. Psychonomic Science, 20, 210-211.

WhitTy, C. W. M., \& ZAnowill, O. L. (Eds.) (1977a). Amnesia (2nd ed.). London: Butterworth.

WhitTY, C. W. M., \& ZANGWILl, O. L. (1977b). Traumatic amnesia. In C. W. M. Whitty \& O. L. Zangwill (Eds.), Amnesia (2nd ed.). London: Butterworth.

ZACHARY, R. A. (1982). Imagery, ambiguity, emotional arousal, and ongoing thought. Journal of Mental Imagery, 6, 93-108.

(Manuscript received May 13, 1983;

revision accepted for publication November $28,1983$. 